\title{
A Staphylococcal Toxic Complex Affecting Particular Areas of the Mitochondrial Electron Transport System
}

\author{
By I. LOMINSKI, C. G. GEMMELL AND J. P. ARBUTHNOTT \\ Department of Microbiology, The University, Glasgow
}

(Accepted for publication 29 November 1967)

\begin{abstract}
SUMMARY
Mitochondrial respiration can be impaired in vitro by a toxic complex, termed succinic oxidase factor (s.o.f.), produced by $70 \%$ of coagulasepositive staphylococci. The oxidation of succinate is most sensitive, cytochrome oxidase less so while succinic dehydrogenase is resistant. The complex consists of at least two components, differing in degree of heat sensitivity. The more heat-resistant component impairs electron transfer in the region of ubiquinone (ubiquinone can reverse the impairment), while the other component impairs electron transfer in the region of cytochrome $c$ (cytochrome $c$ can reverse the impairment). It is thought that the components of s.o.f. may be of enzymic nature, acting on the phospholipids responsible for the integrity of the electron transport chain.
\end{abstract}

\section{INTRODUCTION}

It has been reported that crude toxin from a number of strains of Staphylococcus pyogenes impairs succinic oxidase activity of mouse liver mitochondria. The effect is due neither to alpha toxin nor to other major staphylococcal products; the factor was termed succinic oxidase factor (s.o.f.) (Lominski et al. 1964; Lominski, I966). Apart from impairing mitochondrial respiration, s.o.f. lowers the optical density of a mitochondrial suspension, affects mitochondrial morphology, and is produced by $70 \%$ of pyogenic staphylococci.

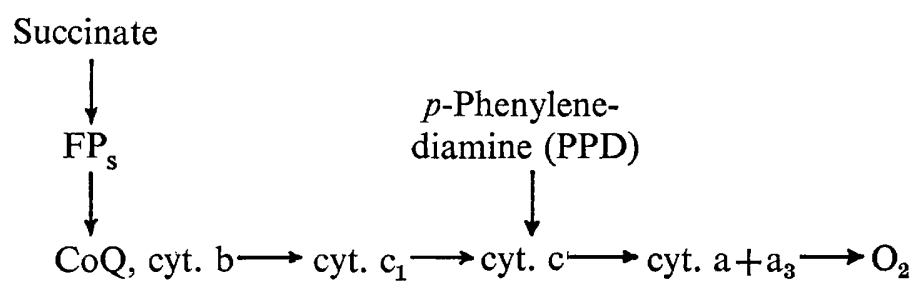

Fig. I.

The present study was carried out to determine the sites of action of the toxin within the respiratory chain. For this purpose the whole chain of succinic oxidase (see Fig. I), as well as two parts of it, i.e. succinic dehydrogenase and cytochrome oxidase, were assayed, adopting as model the scheme of Ernster \& Lee (1964); it is of course realized that the mouse liver mitochondrion may differ in some respects from this model. 
Early experiments showed that at least two sites in the chain were affected by s.o.f. Moreover, later results suggested that these two sites were attacked by two separate components present in crude s.o.f. For simplicity, however, we shall continue to refer to the complex as s.o.f.

\section{METHODS}

Strains. Three strains of coagulase-positive staphylococci of human origin, designated nos. I, 2 and 3 in a previous study (Lominski et al. 1964) were used. Most experiments reported in the present study were carried out with strain no. 2 (NCTC 7I 2 I, wooD 46$)$ phage type $6 / 47 / 53 / 54 / 8 \mathrm{I}$.

Media. For most experiments semi-solid agar containing $2.5 \mathrm{~g}$. Oxoid Nutrient Broth no. 2 and $\mathrm{I} \cdot 0 \mathrm{~g}$. Oxoid Blood Agar Base in $100 \mathrm{ml}$. water (referred to later as medium no. I) was used as a culture medium. Five additional media varying in composition were compared with the standard medium in one experiment.

Preparation of succinic oxidase factor. Semi-solid agar plates were seeded with I ml. of a suspension of staphylococci (c. $6 \times 10^{8}$ organisms) from overnight $5 \%$ horse blood (Oxoid) agar cultures, and incubated for $72 \mathrm{hr}$ at $37^{\circ}$ in an atmosphere of $20 \%$ (v/v) $\mathrm{CO}_{2}$ (adapted from the method of Burnet, 1930). The plates were frozen to $-20^{\circ}$, allowed to thaw at room temperature, the extruded fluid collected, spun at $10,000 \mathrm{~g}$ for I 5 min., distributed in small amounts in bijou bottles, stored at $-20^{\circ}$ and opened only once for use.

Control fluids were obtained by freezing and thawing uninoculated semi-solid agar plates or by autoclaving s.o.f.

Preparation of mitochondria. The bulk of the work was done with mouse liver mitochondria freshly prepared every day by a modification of the method of Schneider (1948). Porton white mice (35-45 g.) were killed by cervical dislocation and exsanguinated. The livers were placed in ice-cold suspending fluid (see below) and after removal of connective tissue by gentle teasing-out homogenized in a Griffith's glass tube by applying Io strokes of a matching plunger. The homogenate was suspended in fluid at the rate of I $\mathrm{g}$. per Io $\mathrm{ml}$. and first spun at $600 \mathrm{~g}$ for $\mathrm{IO} \mathrm{min}$.; the sediment was discarded and the supernatant spun at $8500 \mathrm{~g}$ for $\mathrm{I}$ o $\mathrm{min}$. The mitochondrial sediment was washed in $10 \mathrm{ml}$. of suspending fluid, spun again at $8500 \mathrm{~g}$ for $\mathrm{I} 0 \mathrm{~min}$., finally resuspended in $5 \mathrm{ml}$. and stored for $2 \mathrm{hr}$; centrifugation and storage was at $4^{\circ}$. Immediately prior to use the mitochondrial suspension was diluted $I / 3$ with the same fluid.

Suspending fluids. As a rule the same suspending fluid was used for the preparation of mitochondria, for subsequent dilution in the assay and for dissolving all reagents; in most experiments this was $0.25 \mathrm{M}$-sucrose containing $0.023 \mathrm{M}$-phosphate buffer (Hendry, I948) $\mathrm{pH} \mathrm{7 \cdot 3.} \mathrm{However,} \mathrm{in} \mathrm{some} \mathrm{experiments} \mathrm{mitochondria} \mathrm{were} \mathrm{either}$ prepared and assayed in $0.25 \mathrm{M}$-sucrose containing $0.033 \mathrm{M}$-tris $/ \mathrm{HCl}$ (Gomori, I946), pH 7.4 , or in 0.44 M-sucrose containing $0.02 \mathrm{M}$-disodium citrate (Witter, Watson \& Cottone, 1955), $\mathrm{pH} 6 \cdot 2$.

Assays. An interaction period of $30 \mathrm{~min}$. at $37^{\circ}$ was allowed between s.o.f. or control fluid and mitochondria before tipping the substrate.

All assays were done in duplicate; if values in a pair differed by more than $5 \%$, the experiment was discarded. Where comparison of two enzymic activities, i.e. succinic oxidase and cytochrome oxidase was done, the same batch of mitochondria 
was used for both assays in order to avoid day-to-day variation of mitochondrial preparations.

Succinic dehydrogenase was assayed both manometrically as described by Slater, ( $1949 b$ ), and in Thunberg tubes in the following way: $0.5 \mathrm{ml}$. of mitochondrial suspension was mixed with $\mathrm{I} \cdot 4 \mathrm{ml}$. of sucrose/phosphate buffer and $0.5 \mathrm{ml}$. of toxin or control fluid. The material was then transferred into Thunberg tubes; $0.3 \mathrm{ml}$. of $0.2 \mathrm{M}$-sodium succinate and $0.3 \mathrm{ml}$. of $0.00 \mathrm{I} \mathrm{M}$-methylene blue were introduced into the side-arm. The tubes were evacuated for $5 \mathrm{~min}$. with an Edwards High Vacuum Pump (Model 2 $\mathrm{SC}_{50}$ ) with constant shaking to remove air bubbles, closed, and the contents of the side-arm tipped into the main vessel. The time taken to decolorize c. $90 \%$ of the dye (visually assessed) at $37^{\circ}$ was taken as a measure of dehydrogenase activity.

Succinic oxidase (s.o.) was determined as previously described (Lominski et al. I964), modified from Slater (1949b).

Cytochrome oxidase (c.o.) was assayed manometrically using paraphenylenediamine (PPD) as substrate by the method of Slater (I949a); the mitochondrial suspension oxidized this substrate in the absence of added cytochrome $c$. In the assay $0.5 \mathrm{ml}$. mitochondrial suspension, $\mathrm{I} \cdot 7 \mathrm{ml}$. suspending fluid and $0.5 \mathrm{ml}$. of s.o.f. or control fluid were mixed. After $30 \mathrm{~min}$. $0.3 \mathrm{ml}$. of PPD (O. I5 M) was added from the side-arm.

Succinic oxidase factor activity was measured by comparing the oxygen uptake of s.o.f.-treated and control mitochondria; an impairment of $10 \%$ or more was taken as significant.

Effect of cytochrome $c$. Either at zero time or during the assay of succinic oxidase and cytochrome oxidase systems, $0.3 \mathrm{ml}$. aqueous cytochrome $c$ (crystalline, iron content $0.43 \%$, Koch-Light Ltd.) was added to both control and s.o.f.-treated mitochondria from a second side-arm to give a final concentration of $2 \times \mathrm{IO}^{-5} \mathrm{M}$.

Effect of ubiquinone. $5 \mathrm{mg}$. of ubiquinone (Koch-Light Ltd.) was dissolved in I $\mathrm{ml}$. ethanol and further diluted $\mathrm{I} / 5$ in sucrose/phosphate buffer. Either at zero time or during the assay of succinic oxidase, $0.3 \mathrm{ml}$. of this suspension was added from the second side-arm to both control and s.o.f.-treated mitochondria giving a final concentration of $33 \mu \mathrm{g} . / \mathrm{ml}$. The addition caused an immediate upset of equilibrium within the manometer due to the evaporation of ethanol. This was rectified by opening the manometer stop-cock, resetting the fluid level to zero and allowing I min. for equilibration. The rate of oxygen uptake thereafter was measured in the usual way.

Heating of succinic oxidase factor. The $\mathrm{pH}$ of s.o.f. was adjusted by adding to four parts of toxin one part of 0.15 M-phosphate buffer (Hendry, I948), $\mathrm{pH} \mathrm{7.3,} \mathrm{the}$ mixture heated in a water bath at $60^{\circ}$ for 15 or $30 \mathrm{~min}$., and subsequently diluted for assay to the required strength in sucrose/phosphate buffer.

\section{RESULTS}

Crude preparations of s.o.f. impaired succinic oxidase and cytochrome oxidase. Typical results of the experiments are given in Figs. 2 and 3.

Succinic dehydrogenase, previously reported (Lominski et al. 1964) to be resistant to s.o.f. when assayed both by manometry and by methylene blue reduction was again found to be resistant; $24 \mathrm{hr}$ treatment with s.o.f. gave no impairment. 
The experiments shown below were carried out in sucrose/phosphate buffer. Since phosphate is a well-known mitochondrial swelling agent the effect of s.o.f. on mitochondria, suspended in two other buffers commonly used for the assay of mitochondrial activity, i.e. sucrose/tris/ $\mathrm{HCl}$ and sucrose/citrate (see Methods) was examined; in both, mitochondrial respiration was impaired.

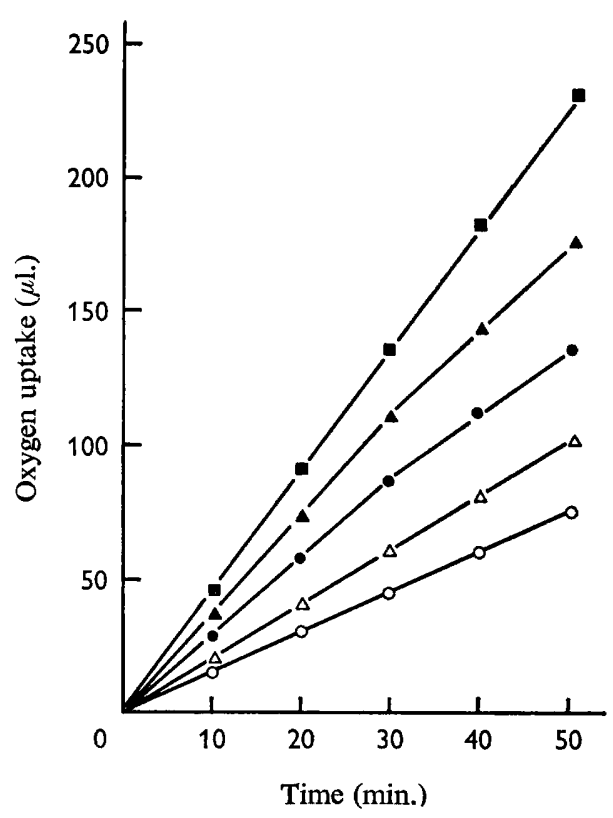

Fig. 2

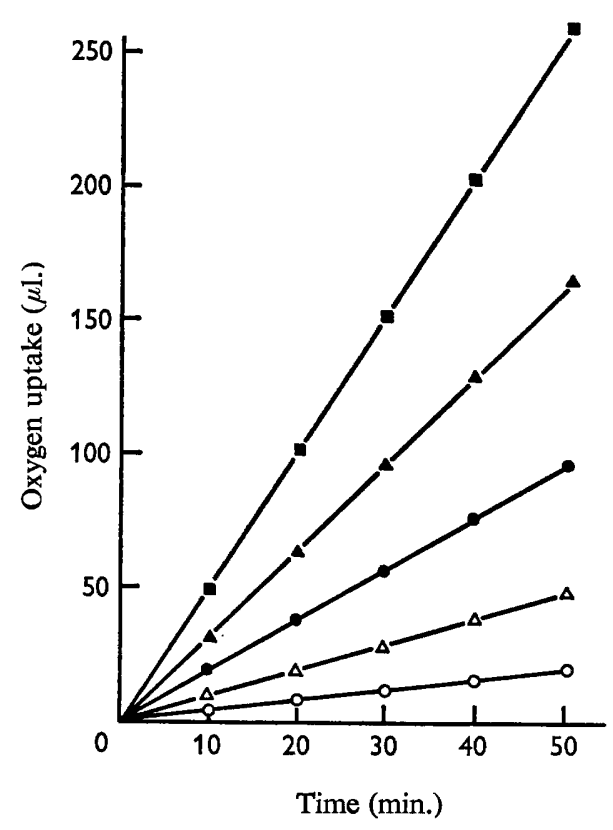

Fig. 3

Fig. 2. The impairment of succinic oxidase: the effect of varying concentrations of s.o.f. $\mathrm{I} / 60$ dilution $\mathrm{O} O$; I/300 dilution, $\triangle \longrightarrow \Delta ; \mathrm{I} / 600$ dilution, $\longrightarrow$; $/ \mathrm{I} 500 \mathrm{dilu}-$ tion, $\mathbf{\Delta} \longrightarrow \mathbf{\Delta}$; control (no s.o.f.),

Fig. 3. The impairment of cytochrome oxidase: the effect of varying concentrations of s.o.f. $\mathrm{I} / 60$ dilution, $\mathrm{O} \longrightarrow \mathrm{O} ; \mathrm{I} / 300$ dilution, $\triangle \longrightarrow \triangle ; \mathrm{I} / 600$ dilution, $\longrightarrow ; \mathrm{I} / \mathbf{1} 200$ dilution, $\mathbf{\Delta} \longrightarrow \mathbf{\Delta}$; control (no s.o.f.), $\boldsymbol{\square} \longrightarrow$ -

When a strain (Wood 46) was grown on our standard medium (see Methods) the ratio of the percentage impairment of succinic oxidase and of cytochrome oxidase at a constant dilution of s.o.f. varied very little from experiment to experiment $(\mathrm{I} \cdot \mathrm{O}-\mathrm{I} \cdot 3)$. However, when this strain was grown on media of differing composition it yielded preparations of s.o.f. with impairment ratios ranging from $I \cdot I 0$ to $2 \cdot 78$ (see Table I). Moreover, when two strains were tested in parallel at two dilutions, the ratios became widely different (see Table 2), revealing a quantitative difference between the two toxins in their ability to impair succinic oxidase and cytochrome oxidase. It can be seen that at a dilution of $I / 60$ the ratio in strain $I$ increased to $I \cdot 66$, while in strain 3 it fell to 0.82 .

Finally, different strains of staphylococci grown on one and the same medium yielded s.o.f. with widely differing impairment ratios. The findings strongly suggested that s.o.f. consists of more than one component. More conclusively this was shown by the following experiments. 
It has previously been reported (Lominski et al. I964) that crude s.o.f. heated at a high $\mathrm{pH}$ to $60^{\circ}$ for $30 \mathrm{~min}$. lost almost completely its activity. An attempt was now made to ascertain whether one component of s.o.f. could not be selectively inactivated by the application of heat under carefully controlled conditions. This proved successful: it was found that heating of s.o.f. buffered to $\mathrm{pH} 7 \cdot 3$, for $\mathrm{I}^{-}-30 \mathrm{~min}$., inactivated

Table I. The ratios of impairment of succinic oxidase and cytochrome oxidase by s.o.f. prepared from Staphylococcus aureus strain WOOD 46 on different culture media at a constant dilution of toxin of $1 / 36$.

$\begin{array}{cccc}\text { Medium no. } & \text { Percent impairment of } & \text { c.o. } & \begin{array}{c}\text { Ratio of } \\ \text { impairment of } \\ \text { s.o. to that } \\ \text { of c.o. }\end{array} \\ \text { I } & 87 & 80 & \mathrm{I} \cdot \mathrm{I} \text {. } \\ 2 & 75 & 29 & 2 \cdot 58 \\ 3 & 84 & 58 & \mathrm{I} \cdot 45 \\ 4 & 89 & 66 & \mathrm{I} \cdot 35 \\ 5 & 93 & 82 & \mathrm{I} \cdot \mathrm{I} 4 \\ 6 & 64 & 23 & 2 \cdot 78\end{array}$

Note: Medium I : Oxoid Nutrient Broth no. 2, 2.5 g.; Oxoid Blood Agar Base no. 2, I g.; water $100 \mathrm{ml}$. Medium 2: Oxoid Nutrient Broth no. 2, 2.5 g.; Oxoid Agar no. 3, 0.3 g.; water, $100 \mathrm{ml}$. Medium 3: Oxoid Blood Agar Base, I•0 g.; saline $100 \mathrm{ml}$. Medium 4: Bacto Tryptone, I $\cdot 0 \mathrm{~g}$.; Bacto Agar 0.6 g.; saline $100 \mathrm{ml}$. Medium 5: Oxoid Tryptone, I.0 g.; Oxoid Agar no. 3, 0.3 g.; saline $100 \mathrm{ml}$. Medium 6: Oxoid Nutrient Broth no. 2, 2.5 g.; Oxoid Blood Agar Base no. 3, 0.3 g.; water $100 \mathrm{ml}$.

Table 2. The ratios of impairment of succinic and cytochrome oxidase by s.o.f. from strains $I$ and 3 tested at different dilutions

\begin{tabular}{|c|c|c|c|c|}
\hline & \multirow{2}{*}{$\begin{array}{c}\text { Dilution } \\
\text { tested }\end{array}$} & \multicolumn{2}{|c|}{ Percentage impairment } & \multirow{2}{*}{$\begin{array}{l}\text { Ratio of impair- } \\
\text { ment of s.o. } \\
\text { to impairment } \\
\text { of c.o. }\end{array}$} \\
\hline & & s.o. & c.o. & \\
\hline Strain I & $\begin{array}{l}1 / 18 \\
1 / 60\end{array}$ & $\begin{array}{l}55 \\
55\end{array}$ & $\begin{array}{l}43 \\
33\end{array}$ & $\begin{array}{l}I \cdot 30 \\
I \cdot 66\end{array}$ \\
\hline Strain 3 & $\begin{array}{l}1 / 18 \\
1 / 60\end{array}$ & $\begin{array}{l}68 \\
27\end{array}$ & $\begin{array}{l}50 \\
33\end{array}$ & $\begin{array}{l}I \cdot 36 \\
0.82\end{array}$ \\
\hline
\end{tabular}

Table 3. Effect of heat on components of s.o.f.

$\begin{array}{lcc}\text { Heat treatment } & \begin{array}{c}\text { Percentage impairment of } \\ \text { oxygen uptake }\end{array} \\ \text { None } & \begin{array}{c}\text { Succinic } \\ \text { oxidase }\end{array} & \begin{array}{c}\text { Cytochrome } \\ \text { oxidase }\end{array} \\ 60^{\circ} / \mathrm{I} 5 \mathrm{~min} . & 75 & 70 \\ 60^{\circ} / 30 \mathrm{~min} . & 62 & 33 \\ & 51 & 7\end{array}$

more of the component affecting cytochrome oxidase than of that affecting succinic oxidase. In only some experiments were we successful in completely inactivating the component which impaired cytochrome oxidase; the thermal resistance of the two components is probably very close. Table 3 shows a typical experiment. 
The question arose whether the two components acted on one and the same site in the electron transport chain or whether more than one site was involved. The answer was provided by the following experiments. When mitochondrial succinic oxidase and cytochrome oxidase activities were impaired by s.o.f. to about $70 \%$ an aqueous solution of cytochrome $c\left(0.3 \mathrm{ml} ., 2 \times 10^{-4} \mathrm{M}\right)$ was added to the reaction vessel from the side-arm. In both systems respiration was for a time restored to a rate close to that of the control mitochondrial preparation. However, the restoration of succinic oxidase was shorter-lived and less complete than that obtained with cytochrome oxidase (see Figs. $4 a$ and $b$ ). In some experiments the rate of oxygen uptake of restored cytochrome oxidase showed distinct tailing off $20 \mathrm{~min}$. after the addition of cytochrome $c$. This, for the time being, remains unexplained although there may be yet another point of attack in the cytochrome oxidase chain.

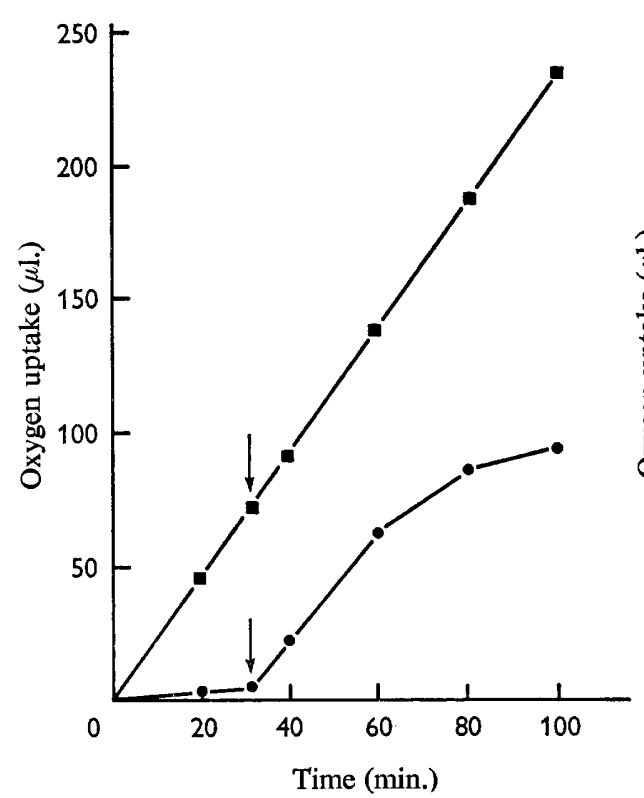

Fig. $4 a$

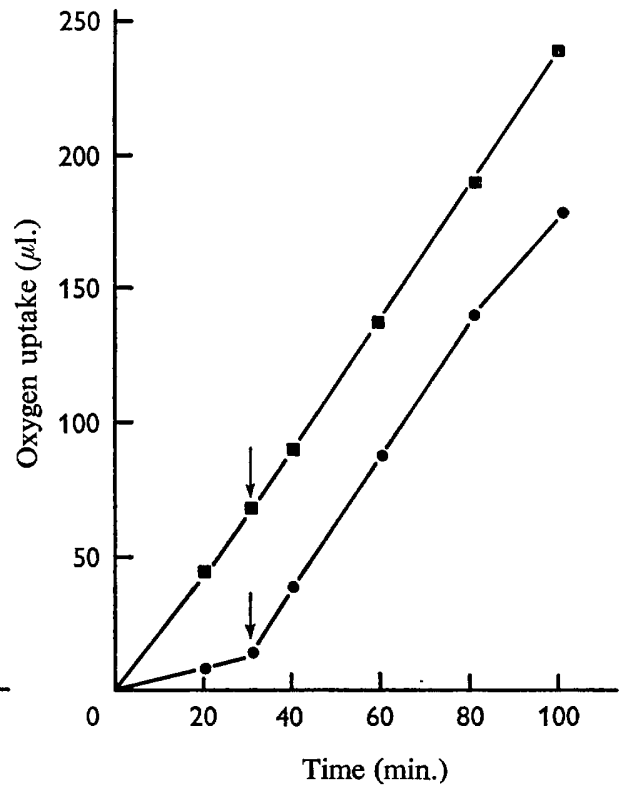

Fig. $4 b$

Fig. 4. Restoration of activity to s.o.f.-impaired mitochondria by cytochrome $c$ : (a) succinic oxidase; $(b)$ cytochrome oxidase. s.o.f.-treated, Cytochrome $c$ added at point indicated by arrows.

The difference in efficacy of restoring the two respiratory systems by cytochrome $c$, an electron carrier common to both, suggested that an additional site involved in the oxidation of succinate might be attacked. With this in mind the effect of another component of the electron transport chain, i.e. ubiquinone (not involved in cytochrome oxidase), was examined in a similar way. Ubiquinone, as expected, did not restore cytochrome oxidase activity but was effective in partially restoring impaired succinic oxidase (see Fig. 5a) though not as completely as did cytochrome $c$. When cytochrome $c$ and ubiquinone were both added simultaneously to s.o.f.-impaired mitochondria, succinic oxidase was almost fully restored (see Fig. $5 b$ ).

Heating experiments (see Table 3 ) showed that the component acting on cyto- 
chrome oxidase is more heat-labile than that acting on succinic oxidase. On the other hand, it is known (Fig. 5a) that ubiquinone restores s.o.f.-impaired succinic oxidase. It seemed logical therefore to assume that the heat-resistant component is the one which attacks the ubiquinone site in succinic oxidase. This indeed was shown by the following experiment: succinic oxidase, impaired by heated s.o.f., could be well restored by ubiquinone (see Fig. $6 a$ ) but no more by cytochrome $c$ (see Fig. $6 b$ ). It follows that the component attacking the cytochrome $c$ locus was almost totally destroyed by heating.

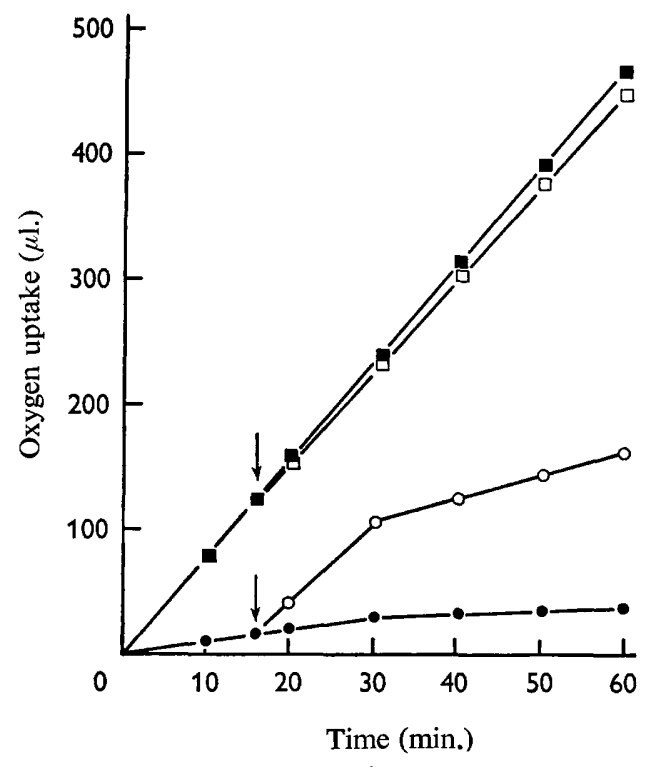

Fig. $5 a$

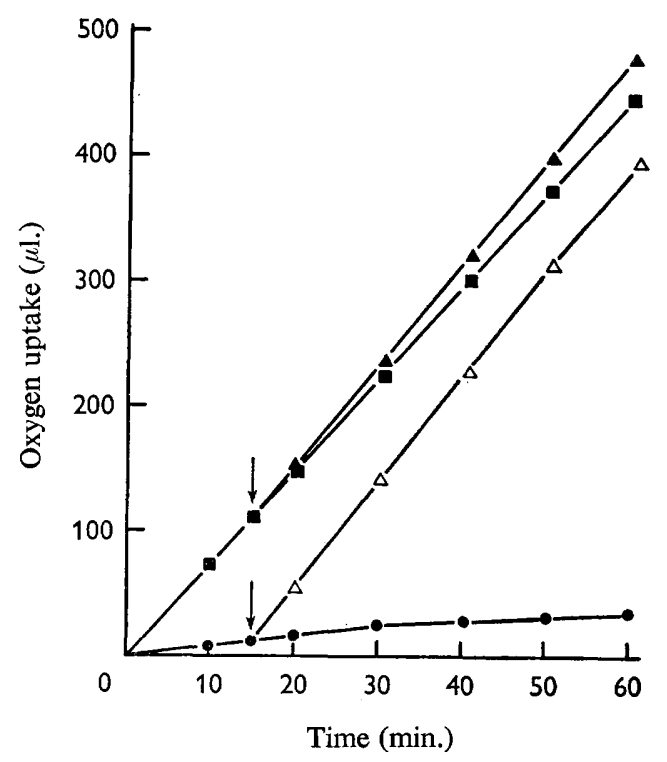

Fig. $5 b$

Fig. 5. Restoration of activity of s.o.f.-impaired succinic oxidase by (a) ubiquinone and (b) ubiquinone plus cytochrome $c$. s.o.f.-treated succinic oxidase, ; s.o.f.-treated succinic oxidase after addition of $(a)$ ubiquinone, $\mathrm{O}-\mathrm{O}$; or $(b)$ ubiquinone plus cytochrome $c, \triangle \longrightarrow \triangle$; control succinic oxidase, $\square-\square$; control succinic oxidase after addition of $(a)$ ubiquinone, $\square-\square$; or $(b)$ ubiquinone plus cytochrome $c, \boldsymbol{\Lambda}-\boldsymbol{\Lambda}$. Ubiquinone $(a)$ and ubiquinone plus cytochrome $c(b)$ added at points indicated by arrows.

It thus appears that s.o.f. contains a heat-labile component acting on the cytochrome $c$, and a heat-resistant one acting on the ubiquinone locus. Attack on the cytochrome $c$ locus causes impairment of both cytochrome oxidase and succinic oxidase-attack on the ubiquinone locus only of succinic oxidase.

The fact that ubiquinone and cytochrome $c$ restore respiratory activity to s.o.f.impaired mitochondria prompted the question whether these components themselves were the substrates of s.o.f. attack and as such were modified in vitro. The following experiments were accordingly carried out. Cytochrome $c$ and ubiquinone were treated with s.o.f. for $30 \mathrm{~min}$. at $37^{\circ}$; their ability to restore respiratory activity to s.o.f.impaired mitochondria was then compared with that of untreated cytochrome $c$ and ubiquinone. The experiments showed that treatment with s.o.f. did not modify either of these substances: s.o.f.-treated cytochrome $c$ and ubiquinone were as active in restoring impaired mitochondrial respiration as were untreated control preparations. 
It has accordingly to be postulated that s.o.f. exerts its effect in the mitochondrion on components other than cytochrome $c$ or ubiquinone, but esential for their intramitochondrial function. These, from preliminary experiments, may be phospholipids.

Finally, in a few experiments (to be reported elsewhere) an attempt was made to study the kinetics of s.o.f.: the results showed that s.o.f. which has acted consecutively on four aliquots of fresh mitochondria quantitatively retained its ability to impair respiration.

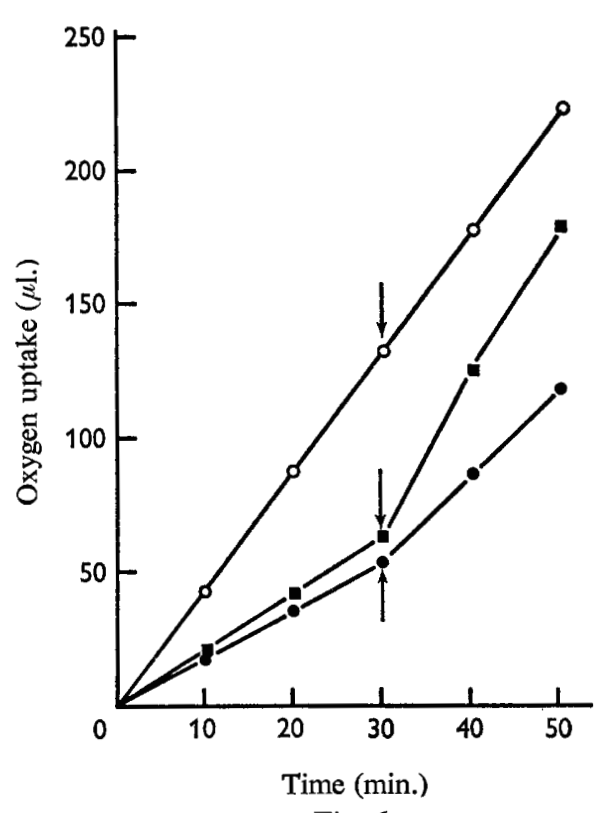

Fig. $6 a$

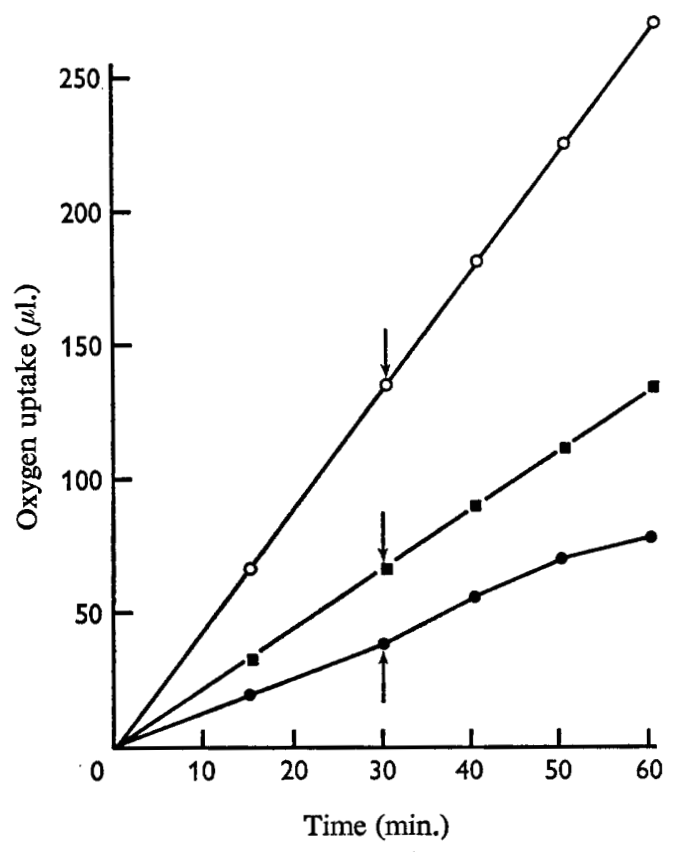

Fig. $6 b$

Fig. 6. Effect of $(a)$ ubiquinone and $(b)$ cytochrome $c$ on succinic oxidase impaired by heated s.o.f. Unheated s.o.f.-treated succinic oxidase, - $\longrightarrow$; heated s.o.f.-treated succinic oxidase, $\square$ - control (no s.o.f.) succinic oxidase, $\mathrm{O}-\mathrm{O}$. Ubiquinone $(a)$ and cytochrome $c(b)$ added at points indicated by arrows.

\section{DISCUSSION}

The greater impairment of succinic oxidase than of cytochrome oxidase by s.o.f. can be accounted for by the finding that s.o.f. attacks two sites in the former and only one in the latter.

The heat sensitivity of s.o.f. and the fact that it is not used up during several successive contacts with fresh mitochondria suggest that the complex is enzymic rather than a blocking agent.

Likely enzymes would be the phospholipases, many of which are known to impair mitochondrial activity: phospholipase A from snake venom (Braganca \& Quastel, I953; Nygaard \& Sumner, I953; Edwards \& Ball, 1954), phospholipase C from Clostridium welchii (Wooldridge \& Higginbottom, 1938; Macfarlane \& Datta, 1954; Edwards \& Ball, I954), and phospholipase D from cotton seed (Tookey \& Balls, I956) 
act by destroying mitochondrial phospholipids. Experiments in progress have shown that s.o.f. attacks both phospholipids and lipids extracted from mitochondria.

The close association of phospholipids with the protein components of the electron transfer chain and their importance to mitochondrial function have been well established (Lester \& Fleischer, 1959, I96I ; Fleischer, Klouwen \& Brierley, I96I ; Fleischer, Brierley, Klouwen \& Slautterback, 1962 ; Brierley \& Merola, I962; Green, 1962; Green \& Fleischer, 1963). Disruption of the phospholipid-protein bonds by detergents such as cholate, deoxycholate and various alcohols produces submitochondrial particles of limited, specific activity (Crane \& Glenn, I957; Hatefi, Haavik \& Jurtshuk, 196I). Harsher treatment (acetone, octanol and ether) abolishes respiration (Fleischer et al. I962; Jacobs \& Sanadi, I955; Lester \& Fleischer, I96I; Szarkowska, I966), which can only be restored to these particles by adding exogenous cytochrome $c$, ubiquinone or phospholipids.

Succinic oxidase factor attacks phospholipids and lipids extracted from mitochondria, cytochrome $c$ and ubiquinone restore activity to s.o.f.-impaired mitochondria, though neither is modified in vitro. We believe at present that s.o.f., by impairing the function of mitochondrial phospholipids, causes dislocation of ubiquinone and cytochrome $c$ : addition of excess exogenous cytochrome $c$ and ubiquinone may either provide by-passes around s.o.f.-affected areas or replace ubiquinone and cytochrome $c$ lost from essential sites of electron transport.

Toxins impairing mitochondrial respiration have hitherto only been found in frankly pathogenic micro-organisms, e.g. the alpha toxin of Clostridium welchii (Macfarlane \& Datta, I954), the plague murine toxin of Pasteurella pestis (Kadis, Ajl \& Rust, 1963; Kadis, Cohen \& Ajl, 1965) and the NAD-splitting enzyme formed by Group A streptococci (Carlson, Kellner \& Bernheimer, I956); s.o.f. was demonstrated in $70 \%$ of pathogenic coagulase-positive staphylococci and only exceptionally in coagulase-negative strains.

There is as yet no evidence that highly purified s.o.f. passes through intact cell membranes. However, it is unlikely that s.o.f. is formed in vivo in the absence of alpha toxin, an agent well known to increase membrane permeability (Artenstein, Madoff \& Weinstein, I963; Cooper, Madoff \& Weinstein, 1964; Rahal, Madoff \& Weinstein, I964); even strains apparently deficient in alpha toxin in vitro do synthesize it in vivo (Foster, I963). In the presence of alpha toxin s.o.f. does indeed cross cell membranes; the consequent impairment of electron transport, of oxidative phosphorylation and of energy release could account for some of the damage caused by staphylococci to the tissues of the host.

The authors wish to thank Mr S. Gray, Mr W. A. Marshall, and Mr I. P. Macvarish for skilled technical assistance, and acknowledge gratefully grants from the Wellcome Research Trust for equipment, the Rankin Research Fund for current expenses, and the Department of State for Scotland for technical assistance and purchase of experimental animals. 


\section{REFERENCES}

Artenstein, M. S., Madoff, M. A. \& Weinstein, L. (I963). Studies of the biologic activity of purified alpha toxin. I. The effect on cells in tissue culture. Yale J. Biol. Med. 35, 373.

Braganca, B. M. \& QuASTEL, J. H. (I953). Enzyme inhibitions by snake venoms. Biochem. J. 53, 88.

Brierley, G. P. \& Merola, A. J. (I962). Studies on the electron-transfer system. XLVIII. Phospholipid requirements in cytochrome oxidase. Biochim. biophys. Acta 64, 205.

Burnet, F. M. (1930). The production of staphylococcal toxin. J. Path. Bact. 33, I.

Carlson, A. S., Kellner, A. \& Bernheimer, A. W. (1956). Selective inhibition by preparations of streptococcal filtrates on the oxidative metabolism of mitochondria procured from rabbit myocardium. J. exp. Med. 104, 577.

CoOper, L. Z., MAdoff, M. A. \& Weinstein, L. (I964). Haemolysis of rabbit erythrocytes by purified staphylococcal alpha toxin. 3, Potassium release. J. Bact. 87, I45.

Crane, F. L. \& GlenN, J. L. (1957). Fragmentation of the electron transport particle with deoxycholate. Biochim. biophys. Acta 24, 100.

EDwARDS, S. W. \& BALL, E. G. (1954). The action of phospholipases on succinate oxidase and cytochrome oxidase. J. biol. Chem. 209, 619.

Ernster, L. \& LeE, C. P. (I964). Biological oxidoreductions. A. Rev. Biochem. 33, 729.

Fleischer, S., Klouwen, H. \& Brierley, G. (I96I). Studies of the electron transfer system. XXXVIII. Lipid composition of purified enzyme preparations derived from beef heart mitochon dria. J. biol. Chem. 236, 2936.

Fleischer, S., Brierley, G., Klouwen, H. \& Slautterback, D. B. (I962). Studies of the electron transfer system. XLVII. The role of phospholipids in electron transfer. J. biol. Chem. 237, 3264 .

FosteR, W. D. (1963). The role of alpha-haemolysin in the pathogenicity of Staphylococcus aureus. J. Path. Bact. 86, 535.

Gomori, G. (1946). Buffers in the range of $\mathrm{pH} 6 \cdot 5$ to 9.6. Proc. Soc. exp. Biol. Med. 62, 33.

Green, D. E. (1962). Structure and function of subcellular particles. Comp. Biochem. Physiol. 4,81 .

GreEN, D. E. \& Fletscher, S. (1963). The role of lipids in mitochondrial electron transfer and oxidative phosphorylation. Biochim. biophys. Acta 70, 554.

Hatefi, Y., HaAvik, A. G. \& Jurtshuk, P. (I96I). Studies on the electron transport system. XXX. DPNH-cytochrome $c$ reductase. Biochim. biophys. Acta 52, 106.

HENDRY, E. B. (I948). The preparation of iso-osmotic phosphate buffer solutions. Edinb. med. J. 55,142 .

JACOBS, E. E. \& SANADI, D. R. (I955). Some components of the oxidative phosphorylation system. Biochim. biophys. Acta $\mathbf{1 7}, 29 \mathrm{I}$.

Kadis, S., AJL, S. J. \& Rust, J. H. (1963). The action of plague murine toxin on mitochondria from resistant and susceptible animals. J. Bact. 86, 757.

Kadis, S., CoHEN, M. \& AJL, S. J. (1965). The effect of plague murine toxin on the electron transfer system. Biochim. biophys. Acta 96, I79.

Lester, R. L. \& Fleischer, S. (I959). The specific restoration of succino-oxidase activity by coenzyme $\mathrm{Q}$ compounds in acetone-extracted mitochondria. Archs Biochem. Biophys. 80, 470.

LESTER, R. L. \& FLEISCHER, S. (I96I). The respiratory activity of acetone-extracted beef heart mitochondria. Biochim. biophys. Acta 47, 358.

LomINSKI, I. (1966). Biologically active metabolites of Staphylococcus pyogenes. In Wound Healing. Ed. by Sir Charles Illingworth. p. I07. London: J. and A. Churchill, Ltd.

Lominski, I., Arbuthnott, J. P., Gemmell, C. G., Gray, S. \& Marshall, W. A. (1964). Impairment of succinic oxidase of mouse liver mitochondria by a factor produced by Staphylococcus pyogenes. Lancet ii, 503.

Macfarlane, M. G. \& DatTA, N. (I954). Observations on the immunological and biochemical properties of liver mitochondria with reference to the action of Clostridium welchii toxin. Br. $J$. Exp. Path. 35, I9I.

NygaARd, A.P. \& Sumner, J. B. (I953). The effect of lecithinase A on the succinoxidase system. J. biol. Chem. 200, 723 . 
Rahal, J. J., Madoff, M. A. \& Weinstein, L. (1964). Effect of staphyloccal alpha toxin on rabbit kidney tissue culture cells. Fedn Proc. Fedn Am. Socs exp. Biol. 23, I9I.

SCHNeIDER, W. C. (1948). Intracellular distribution of enzymes. III. The oxidation of octanoic acid by rat liver fractions. J. biol. Chem. 176, 259.

SLATER, E. C. (1949a). The measurement of the cytochrome oxidase activity of enzyme preparations. Biochem. J. 44, 305.

Slater, E. C. $(1949 b)$. A comparative study of the succinic dehydrogenase-cytochrome system in heart muscle and in kidney. Biochem. J. 45, I.

SzarkowsKa, L. (1966). The restoration of DPNH oxidase activity by coenzyme Q (ubiquinone). Archs Biochem. Biophys. II3, 519.

ToOKey, H. L. \& Balls, A. K. (1956). Plant phospholipase D.2, Inhibition of succinic oxidase by cottonseed phospholipase D. J. biol. Chem. 220, I5.

Witter, R. F., Watson, M. L. \& Cottone, M. A. (1955). Morphology and ATP-ase of isolated mitochondria. J. biophys. biochim. Cytol. I, 127.

Wooldridge, W. R. \& Higginbortom, C. (I938). The effect of certain bacterial toxins upon some respiratory mechanisms of animal tissues. Biochem. J. 32, 1718 . 